\title{
Do Deep Disagreements Motivate Relativism?
}

\author{
Victoria Lavorerio ${ }^{1,2}$ (1) \\ Published online: 22 May 2018 \\ (c) The Author(s) 2018
}

\begin{abstract}
In his 2014 article "Motivations for Relativism as a Solution to Disagreements", Steven Hales argues that relativism is a plausible disagreement resolution strategy for epistemically irresolvable disagreements. I argue that his relativistic strategy is not adequate for disagreements of this kind, because it demands an impossible doxastic state for disputants to resolve the disagreement. Contrarily, Fogelin's (Informal Log 7(1):1-8, 1985) theory of deep disagreement does not run into the same problems. Deep disagreements, according to Fogelin, cannot be resolved through argumentation because the conditions for argumentation are lacking in such contexts. I advance the view that deep disagreements arise due to differences in disputants' mutually supporting interrelated beliefs. This view avoids the hurdles caused by the tiered structure of support found at the heart of Hales's view on disagreement: the assumption that belief and perspective can be separated, and that disagreement is located (in the latter).
\end{abstract}

Keywords Deep disagreements $\cdot$ Relativism $\cdot$ Hales $\cdot$ Fogelin $\cdot$ Disagreement resolution

\section{Introduction}

The relation between disagreement and relativism in epistemology is currently receiving a good deal of attention. This interest is partly explained by a resurrection of relativistic theories in epistemology, as epistemologists link the possibility of deep disagreement with the plausibility of relativism $^{1}$ (Boghossian 2006; Pritchard 2011; Baghramian and Carter 2017). The connection between deep disagreements and epistemic relativism comes from epistemologists' conceptualizing deep disagreements in the lines of fundamental epistemic differences between the disputants. ${ }^{2}$ Fundamental epistemic differences can be cashed out in terms of principles (Boghossian 2006; Lynch 2010, 2012), perspectives (Hales 2004, 2006, 2014), sources (Hazlett 2013), hinges (Pritchard 2011), etc. Mainstream epistemologists claim that these epistemic resources inform us whether we are warranted in believing a proposition (because e.g. comes from a reliable source). So, when disagreeing parties appeal to different fundamental epistemic resources which provide warrant for believing contradicting propositions, the disputants

\footnotetext{
Victoria Lavorerio

vicc_lav@hotmail.com

University of Vienna, Vienna, Austria

2 Vienna, Austria
}

will not be able to settle their differences epistemically, as they do not have an epistemic common ground. If this kind of disagreement is possible, then fundamental epistemic differences between people seem to invite relativistic theories.

In accordance with this line of thought, Hales argues that relativism can not only explain why deep disagreements arise, it can also resolve them. Thus, it is not just deep disagreements being possible (and actual) that motivates relativism, but a further motivation is that relativism is the most plausible strategy for resolving them. In this article, I analyse Hales's view and argue that, despite appearances, the relativistic strategy cannot resolve the kind of disagreement he is concerned with. It has to be noted that my argument concerns disagreement from the perspective of the participants, not the theorist. In this I follow Hales's lead.

After explaining why I think Hales's strategy fails, I introduce a different take on deep disagreements: Fogelin's 1985 paper "The Logic of Deep Disagreement". Hales's and Fogelin's accounts do not contradict each other. In fact, there are many similarities between them, as we shall see in what follows. However, what Fogelin's view (or more precisely, a particular interpretation of his view) brings to the table,

\footnotetext{
${ }^{1}$ For an opposing view, see Rovane (2011), who argues that relativism is a metaphysical theory and cannot be motivated by the epistemological fact that we cannot adjudicate in some disagreements.

${ }^{2}$ What Kinzel and Kusch (2018) call "fundamental disagreements".
} 
can help elucidate why Hales's strategy fails. To start with, Fogelin would deny that resolution is possible in the example Hales uses. Like Hales, Fogelin sees the radical differences between the disputants' positions as the cause for the intractability of the disagreement. Unlike Hales, Fogelin takes these differences to be in the systematic nature of beliefs, rather than in a more fundamental epistemic resource. This a subtle divergence, but not insignificant. When dislocating the tiered picture in favour of a lateral support one, epistemologists can stay clear of the misleading assumptions regarding disagreement which seem to favour relativism as a resolution strategy.

In Sect. 1, I present Hales's argument: I review which resolution strategies he considers and how he characterizes the kind of disagreement he is concerned with. In Sect. 2, I lay down my reasons to reject Hales's relativism as a resolution strategy for this kind of disagreement. In short, I believe his relativistic theory forces upon the disputants a doxastic demand which is impossible for them to meet. Finally, in Sect. 3, I explore what I consider a more successful account of the phenomenon, inspired by Fogelin's theory of deep disagreements.

\section{Hales's Argumentation}

Hales's argument has the following form: if there is a kind of disagreement such that: (a) relativism gives a promising resolution of it, while (b) the other resolution strategies fail, then considerations of this kind of disagreement make relativism more plausible.

What are the other resolution strategies available? According to Hales: capitulation, compromise, ambiguity, and Pyrrhonism. If we find ourselves having a disagreement, then we can present our respective arguments until one of us concedes the other the "victory", that is, the approach Hales describes as "keep arguing until capitulation" (Hales 2014, 74). Another way to resolve our disagreement is if each of us compromises and come to see that we both may have been partly right and partly wrong. Or, in other cases, we realise that our disagreement has arisen from an ambiguity in how we use the terms or how we interpret the situation. Once the ambiguity is recognised, the disagreement is resolved (or rather dissolved). If our disagreement is such that our best arguments and evidence aren't enough to sway the balance either way, we have discarded ambiguity as its origin, and there seems to be no room for conciliation, then a resolution strategy available to us is what Hales calls Pyrrhonism.

Hales describes Pyrrhonism as: "suspending judgment without hope of leaving the state of suspension" (2014, p. 68). He goes on to characterise the position as one where " $[\mathrm{c}]$ ontrary claims are regarded as equally credible or discredible, and the skeptic is content to report only appearances, or how things seem to her. (...) Really, the skeptic has no idea what to believe, and so removes from the fray altogether" (2014, p. 68).

Besides capitulation, conciliation, ambiguity, and Pyrrhonism, Hales considers a further disagreement resolution strategy: relativism. He claims that relativism can be motivated when it is intuitively the most appropriate response to a certain kind of disagreement. However, since "intuitions vary" (p. 71), it is necessary not only to show that relativism can account for such disagreements, but that the competing strategies give "especially unappealing answers" (p. 72). ${ }^{3}$

The kind of disagreement Hales thinks is necessary to motivate relativism is one where the irreconcilable differences between the disputants are epistemic in nature. The epistemic nature of the irresolvability affects the disagreement at various levels.

1. disputants disagree over whether a proposition is true,

2. disputants disagree over the kind of evidence that is relevant to settle the dispute,

3. there is no agreed upon method to resolve the dispute over what kind of evidence is relevant.

As Hales points out, disagreement over what kind of evidence is relevant is not enough to have an epistemically irresolvable disagreement, if we can find an agreed-upon way to evaluate the appropriateness of the evidence. It is when this mechanism fails that we run into problems. Hales presents the example of a Christian (Diane) and a philosopher (Jack) who disagree about whether there is an immortal immaterial soul. Not only do they base their respective beliefs on different kinds of evidence, but they cannot think of a way to make one kind of evidence prevail over the other.

In these cases, the reviewed resolution strategies fail. The possibility of capitulation looks bleak, not because the participants aren't willing to revise their beliefs (let's suppose they are), but because if one side appeals to evidence the other doesn't consider relevant (or doesn't consider evidence at all), then their positions remain untouched by the force of the other party's arguments. Although there are cases where ambiguity over terms can generate an initial disagreement of this sort, it is unlikely that once the parties have presented and evaluated their arguments and evidence, the ambiguity continues to go unnoticed. Compromise, I agree with Hales, doesn't look promising either, since it is not clear what part of admitting you are partly right would not make me admit I am completely wrong. To motivate Pyrrhonism, Hales tells

\footnotetext{
${ }^{3}$ Along these lines should be understood Hales's rejection of disagreements over taste judgements as a promising case for relativism; even if it is granted that relativism gives a promising account of disagreements of this kind so do the other strategies (Hales 2014, p. 77).
} 
us, we could reevaluate the example as a case where we either "can't get enough second-order evidence to determine what the appropriate first-order evidence is", or we "can't get the right kind of second-order evidence" (p. 81). Although a decisive argument against these strategies is admittedly hard to find (Hales writes: "I don't know how to decisively rule out this interpretation", p. 81), it is just as hard to imagine what such evidence would be.

\section{Problems with the Relativistic Resolution Strategy}

Hales tells us that "provided we are not tempted by scepticism, relativism appears to be our last option" (2014, p. 81). Relativism, as opposed to Pyrrhonism, does not prescribe suspension of judgement. This is because the truth-value of the target proposition (the belief disputants disagree about) is relative; thus, both disputants are epistemically right in holding their doxastic attitude (belief or disbelief) towards it. Hales describes the relativist resolution strategy as follows:

"The dispute between Jack and Diane is resolved by determining that $\mathrm{P}^{\prime}$ is both true and false. $\mathrm{P}^{4}$ is true relative to Diane's perspective, a perspective which includes as an epistemological component the methodology of appeal to revelation, the Bible, and its expert interpreters as a source of noninferential beliefs. $\mathrm{P}^{\prime}$ is false relative to Jack's perspective, the epistemology of which includes analytic rationalism." (Hales 2014, p. 81).

In a relativistic account of disagreements, the proposition the parties disagree about is neither true nor false simpliciter, but true relative to one perspective and false relative to the other. Each disputant has a different epistemic perspective (which for Hales include methods of delivering noninferential beliefs) in virtue of which their respective beliefs are true. Therefore, a relativistic strategy can account for the intuition that there is something irresolvable about the disagreement, and at the same time, that its participants are not epistemically blameworthy for the disagreement's being irresolvable. For Hales, the disagreement persists because the disputants don't have any principled way to settle the question of which kind of evidence is relevant. Such a question

\footnotetext{
4 "P"" is the target proposition the disputants disagree about, in Hales's example it stands for "human beings each have a soul which animates their bodies and is immortal; it does not perish when it separates from the body at death, and it will be reunited with the body at the final Resurrection" (2014: 79). I believe nothing substantial is lost if I replace this with the simpler "humans have souls". If this proposition is deemed too vague, then refer to Hales' as the target proposition.
}

cannot be settled because it has different answers in different epistemic perspectives.

Understood as a disagreement resolution strategy, relativism amounts to letting disputants know how they are right and how they are wrong; they are right in their doxastic attitude towards the target proposition (belief and disbelief), they are wrong in not recognizing that the truth-value of the target proposition is relative, rather than absolute. Resolution comes from realizating the relative truth of their counterpart's belief. Thus, for relativism to be a promising resolution strategy, participants must, at least in principle, come to terms with the conditions of this "peacemaking" (p. 69) strategy. It is here where I find the Achilles' heel of relativism as a theory of irresolvable disagreements: it demands an impossible epistemic judgement from the disputants for them to accept the resolution of the disagreement.

There are cases where relativism makes sense as a disagreement resolution strategy. For example, cases where we relativize our claims to goals: if $g$ is the goal, then the proposition, $p$, " $m$ is the right way to proceed" is true; but if $h$ is the goal, then the proposition is not true. Later we can argue which goal is adequate, whether $g$ or $h$, but that will be a different dispute altogether; regarding the question of whether $\mathrm{p}$ is true we can agree that it is relatively true. We also relativize to interpretations: "provided my interpretation of the poem, $p$ is true, provided your interpretation, $p$ is false". Again, we can then discuss which interpretation is better, but that won't affect the consideration that whether $\mathrm{p}$ is true or not is relative to whatever interpretation we choose. In these and other cases, we separate (with more or less success) "perspectives" or "standards" from the target proposition which depends on them. Hales's example, nevertheless, is not one of these cases.

Let us revisit the example of an interpretation-based disagreement. If I see your interpretation of the poem as plausible, though I have reason to believe it is not accurate, then it makes sense for me to say: " $p$ is true relative to your interpretation". If on the other hand, I am not willing to countenance your interpretation (because it is incoherent and//or contradicts the evidence), then " $p$ is true relative to your interpretation" would be tantamount to " $p$ is false". Each amounts to the claim that "p would be true, on -- or given -- your interpretation," though in the former case I am willing to countenance your interpretation, while in the latter I am not. To be clear, it is perfectly reasonable to argue that $\mathrm{p}$ is true only relative to some interpretation, then argue that such interpretation is unviable. But the result would obviously be that $\mathrm{p}$ is false, not that it is relatively true. Thus, relative truth needs viable standards upon which to relativize (interpretations, perspectives, epistemic systems, etc). If relativism has any chance to be a resolution strategy, then the parties must regard the other party's perspective as plausible, 
though wrong. Otherwise, the difference between "relatively true" and "plain false" would be lost on them.

One worry that may arise at this point is that the demand for disputants to see each other's perspectives as tenable is too strong. Perhaps all that is necessary for relativism is that the other perspective is seen as ineluctably foreign, and thus, epistemically inaccessible from one's own perspective. This is certainly the case for the participants of deep disagreements; disputants see each other's perspectives as foreign and inaccessible (consider basing your beliefs concerning the existence of souls on what the Bible says if you do not believe in the Christian God).

But for this intellectual distance to deliver relativism, it would have to be thought of as a strong incommensurability between perspectives: "Your perspective is so alien to my way of thinking, that I cannot judge it to be tenable, but, for the same reason, I cannot judge it to be untenable. So, I might as well consider you to be right relative to it". However demanding perceived tenability may be, it is an even stronger demand for the distance between perspectives to be so radical that reasonable assessment across perspectives is rendered impossible. Disputants can feel strongly removed from the other's perspective, and still feel completely comfortable judging it. To insinuate that the divide is so deep seems unwarranted. ${ }^{5}$

A relativistic resolution strategy can be the appropriate response to many disagreements. However, in the example Hales proposes, I don't see how such view can be tenable. Let me explain why.

Even though the relativistic strategy seems at first look to be permissive to the disputants ("declaring everyone is a winner", Hales 2014, p. 68), in fact, it demands too much of them. For a disagreement to be resolved through the relativistic route, the disputants must:

(a) concede that, contrary to what they previously thought, the truth-value of the proposition they disagree about is not absolute, but relative;

(b) concede that the epistemic perspective of their adversary (which for Hales includes methods of acquiring non-inferential beliefs) is prima facie tenable (because taking it as true relative to an untenable perspective is the same as taking it to be false);

\footnotetext{
5 Hales himself doesn't seem to endorse this view: "The question 'how can I get into Heaven?' has a meaning within the Christian perspective, a meaning that even an atheist can recognize. Likewise, the range of possible answers to the question includes ones that are comprehensible to those not adopting a Christian perspective. The answers 'salvation is preordained by God, there is nothing you can do' and 'personally accepting Jesus as Lord is your ticket to paradise' are perfectly understandable answers to an atheist, just not ones that could be accepted as true description of reality" (Hales 2006, p. 112).
}

(c) maintain their belief as strongly as before the disagreement unfolded (if the disputants change their doxastic attitude as a consequence of the disagreement, then it is not a relativistic resolution, but compromise, capitulation, or Pyrrhonism).

(a) Is the relativistic thesis; I will not argue either for or against it, as my focus is not on the truth-value of the proposition the disagreement is about, but rather on the intuitions regarding its resolution. On the other hand, I do have a problem with the joint attainability of (a), (b), and (c). Because the disagreement was resolved through the relativistic strategy, the disputants learned (a) and (b) as a result. According to the relativistic story, the disagreement made it evident for the disputants that their beliefs are only true relative to their own perspective (a) and that a perspective holding a contradictory belief is also plausible (b). However, their doxastic attitudes, according to Hales's diagnosis, remain untouched even after learning these important features of their epistemic predicament (c). Why aren't these considerations enough for the disputants to lessen their commitment to their antecedent belief? Even if the relativist reassures us that they are epistemically permitted to hold on to their beliefs (because their epistemic perspectives allow them to), this consideration may not be enough for the disputants to feel safe from the sceptic pull. ${ }^{6}$

I judge this to be an important challenge the relativist must face. Nevertheless, I do think there is room for the relativist to move. But regardless of whether the relativist has a compelling case to guarantee the joint attainability of (a), (b), and (c), the relativistic strategy still fails to deliver a plausible disagreement resolution. This is because there is a further condition the relativistic strategy demands from the disputants:

(d) each disputant must separate the proposition believed by her adversary from the epistemic perspective that motivates and justifies it, while taking the proposition to be false and the perspective to be tenable.

\footnotetext{
${ }^{6}$ This argument resembles Boghossian's "Argument from (Perspectival) Immersion" (2011, pp. 61-64). It also shows the tension between the conditions of disagreement seen as motivation for relativism (his concern being faultless disagreement). But Boghossian's argument targets the stability of condition (b): how it can be judged that the other has not made a mistake and that her perspective is not faulty (given (a) and (c)). Alternatively, I grant (b), following Hales, and wonder how (c) could be retained. Nevertheless, in my next argument, where I discuss further condition (d), the argumentation shifts drastically, as (d) is rather a precondition for a relativistic treatment of disagreement along the lines Hales offers.
} 
This is the kind of doxastic state I find impossibly hard to achieve, and which, in my eyes, sways the balance against the relativistic account.

Taking the philosopher of Hales's example, Jack: he would have to separate the Christian doctrine from the belief in the existence of souls. But, this separation strikes me as artificial; the Christian theory of the soul is not a corollary belief, but an essential part of the system; the belief is entangled with other parts of the doctrine from where it gains support, like the relationship between God and men, the moral experience, the afterlife, etc.

Jack would also have to judge the Christian perspective as tenable while at the same time maintain that the proposition "humans have souls" is false. What remains of the perspective once the target belief is considered false? According to Hales, what remains is the method with which we get our non-inferential beliefs. In the Christian perspective, Hales tells us, we get to non-inferential beliefs by the method of revelation. ${ }^{7}$ Revelation is the passing of divine truths to humans by God itself. It takes two forms: either God revealed itself only to some people in the distant past, whose experiences are recorded in the sacred scriptures, or all humans have an innate capacity to feel the Holy Spirit guiding us towards the truth. Following Hales, I will consider the former option. Since the people God revealed to are long dead, all we have as a way to those revealed truths are their stories as written in the Bible. Thus, Hales tells us (2014, p. 79), in the Christian perspective, the Bible (because of its being an expression of the revealed word of God) is a source of basic beliefs.

Is it possible to take the Bible as a plausible source of non-inferential beliefs (i.e. taking the Christian perspective as tenable) and still believe that humans don't have souls? We might be tempted to answer this question positively if we changed the target belief. Consider the proposition "homosexuality is wrong". We can certainly take the Bible as a possible source of evidence to decide whether this proposition is true or not, and then argue that it is false. A Christian doctrine where homosexuality is not immoral makes sense; a Christian doctrine without souls, on the other hand, would not be the doctrine we know. The doctrine relies so heavily on the existence of souls, it is hard to make sense of without it. If I take the Bible to be a source of evidence, then I cannot but believe there are souls.

Now, is it possible to believe that souls do not exist, and still consider the Bible as a plausible source of non-inferential beliefs? We might be tempted to give a positive answer if we consider that we read Plato as a source of wisdom, even as disbelievers of the existence of platonic forms (or souls

\footnotetext{
${ }^{7}$ See Hales, 2006, Chap. 2.
}

for that matter). Why shall we do so with Plato but not with the Bible? The difference is that we don't rely on Plato's work to deliver non-inferential beliefs; that is, we don't read Plato as if it were the Bible (or any other sacred book). This is characteristic of the philosophical method (or of its many methods); we take Plato's work with the utmost respect as a founding father of philosophy, and yet, take everything in his works as up for criticism. Philosophical thought allows us to take Plato as a source of inspiration, wisdom, argumentative achievement, but never as a source of non-inferential beliefs.

Whereas the Bible is not up for criticism in the same way; it is taken, at least according to Hales, as a source of basic beliefs. But if I don't believe that there are souls, what would it mean for me to rely on a book that hinges on the existence of souls to deliver basic beliefs? ${ }^{8}$ My disbelief in the existence of souls precludes me from taking the Bible as a source of non-inferential beliefs (though I could still take it a source of inspiration or general guidance), and thus from taking such perspective as tenable.

Perhaps this is too strong; surely one could regard someone else as wrong but reasonable. In the same vein, the disputants could regard their counterpart's perspectives as false but tenable. For instance, Jack could see Diane's belief as reasonable because she took the right doxastic steps within her general epistemic perspective. In this case, Jack would assume the following conditional precept of epistemic rationality: if one takes revelation to be a proper basic belief-acquisition method, then belief in the existence of souls would be reasonable. However, I find this conception of epistemic rationality too weak. The relevant question is whether Jack could see reliance on revelation as rational to begin with. I believe that whether he can or not will hinge on whether he finds the basic tenets of Christianity to be plausible.

One could hold a false belief, even a host of false beliefs, that have been acquired in a way that does not violate norms of rationality. A clear case would be reasoning properly but based on misleading evidence. For instance, after watching a "mockumentary", you mistake it for a proper documentary and come to believe many false propositions based on it. Sometimes, though, the misjudgment over what counts as evidence for what is so gross, it could hardly be judged to be reasonable thinking.

\footnotetext{
${ }^{8}$ I suspect it to be an oversimplification, as interpretations of the Bible are generally complex mixtures of passages interpreted literally, passages taken as parables, metaphors, or myths, and parts dismissed as idiosyncratic of its epoch, carrying little to no weight today. The Christian Hales uses, and the one I take from him, is a stereotypical Christian. But the nuances of the doctrine may be relevant to a possible argumentative exchange. Regardless, the existence of the soul still seems such a core ingredient of the faith, this story may still hold true.
} 
In the 2014 movie, "Kumiko, the treasure hunter", a young Japanese woman travels to Minnesota to search for a briefcase full of money buried somewhere along a road. She does so because she watched the Coen brothers' movie "Fargo", and concluded that since in the movie the money goes undiscovered, the briefcase may still be there. She proceeds methodically and diligently in her quest for the actual location of the "treasure" by obsessively watching the scene where the case is buried, and trying to determine its location. I would not deem her belief that a suitcase full of money is buried somewhere in Minnesota rational; she is so wrong about the nature of the material she is watching, it does not make sense to reason based on such mischaracterization (compare with the case of the mockumentary, where the viewer also midjudges the nature of the material, but such blunder is not a breach in rationality). I want to say that, from Jack's perspective (a philosopher of mind who has spent a good deal of time arguing against the existence of an immaterial substance inside human beings), taking the Bible (which relies heavily in the thesis of the existence of souls) as a source of basic beliefs, would be analogous to taking a fictional movie as a map of a secret treasure.

The same could be said, mutatis mutandis, from Diane's perspective:

"We will not be able to correctly understand the nature of the self, devise a true theory of mentality, know how to behave in matters of sexual and medical ethics, or develop an accurate and comprehensive theory of justice without the aid of revelation. Revelation is needed to supply the data upon which reason can then operate. Trying to do philosophy without the input of God is a fool's errand." (Hales 2006, p. 67).

One can be wrong and rational, but when one bases one's reasoning on wildly mistaken premises, it is difficult to see how rationality could be retained. I take these comments as judgements on neither the rationality nor the truth-value of the beliefs of the characters in the example. My reasoning is restricted to how these characters would judge each other.

In conclusion, for relativism to resolve disagreements, it must posit a separation of perspective and target belief, so that a disputant can judge their counterpart's perspective as tenable while also judging the belief to be manifestly false. However, in cases of epistemically irresolvable disagreements, the belief is so central to the perspective that the two rise and fall together. It is inappropriate to settle the dispute by saying that each party is right according to their own perspective or epistemic system, since it is exactly the validity of the perspectives as means to justify the contradicting proposition that is at stake.

\section{A Better Conception of Deep Disagreements}

Although Hales makes no reference to it, his reconstruction of an epistemically irresolvable disagreement is in the neighbourhood of Fogelin's (1985/2005) "deep disagreements". For Fogelin, deep disagreements are non-normal disagreements; their participants lack the background of shared beliefs and preferences participants in normal disagreements enjoy. This background constitutes the framework within which reasons can be deployed, considered, and contested given the mutual understanding of what constitutes appropriate reasons in a certain context. Because common ground is a precondition for argumentation, deep disagreements, Fogelin claims, are not resolvable by rational means. ${ }^{9,10}$ As a consequence, there is only room for non-rational strategies of resolution, such as persuasion, pragmatical reasoning, bargaining, intimidation, etc.

I appeal to Fogelin's theory in my criticism of Hales for two reasons. (1) Fogelin views deep disagreement as irresolvable by argument, which is, I believe, the right conclusion a relativist should draw from these cases. (2) For diagnostic purposes, it is useful to compare how each author conceptualizes the phenomenon at hand. For Hales (and for other epistemologists), these disagreements occur due to differences on a fundamental level (epistemic principles, perspectives, sources, etc.). This tiered conception leads to two interrelated assumptions: that separation between belief and perspective is possible, and that the disagreement is located in the latter. Fogelin, however, can be read as opposing such diagnosis, and thus, as offering an alternative reading of how deep disagreements arise.

In the remainder of the paper, I present my case for these two points. First, I analyse Hales's conceptualization of deep disagreements. Next, I discuss the resolvability of deep disagreements. Then, I contemplate a tiered interpretation of Fogelin's remarks in terms of framework propositions, to later decide on a different interpretation of how he sees deep disagreements.

\subsection{Tieredness, Separatedness, and Locatedness}

In the first part of this paper, I examined the relativist stance defended by Hales which claimed that in certain

\footnotetext{
9 Turner and Wright (2005) rightly note that Fogelin conflates rational means of resolution with argumentation (see fn 11 below).

10 This is a factual claim that can be challenged. It can be argued that if there were disagreements with the characteristics Fogelin mentions, then they would be irresolvable, but there aren't. For example, Finocchiaro (2013) distrusts Fogelin's construal of the debates mentioned as examples of deep disagreements (abortion and affirmative action quotas).
} 
disagreements the disputants ought to regard their counterparts as right relative to a perspective that is not their own. This stance at first glance has an intuitive appeal; after all, we are sometimes inclined to grant reasonableness to our opponent across the aisle, especially in speculative matters such as philosophy. However, if my reasoning was correct, disagreements cannot really be resolved through this strategy. Why is this possibility so intuitively attractive then? Why does it seem plausible to resolve disagreements this way?

In this section, I review an explanation for this, namely, that the relativist intuition emerges from the way the structure of these disagreements is conceptualized. That is, by regarding our doxastic methods as a layered affair, we come to see our disagreement as located not in the level of our beliefs, but in a deeper level (of fundamental doxastic resources). This picture is the result of the interplay of three assumptions I call tieredness, separatedness, and locatedness.

It is these assumptions, I will argue, which make it seem possible to judge our opponents as right relative to a deeper level that we do not share.

Even if his relativistic structure of justification is not fully developed in his 2014 paper (see Hales 2006), the paper nevertheless offers a succinct reconstruction of the view: "irreconcilable differences are to be located at the level of independent methods of generating noninferential beliefs which are then used as basic data for building theories that one holds in reflective equilibrium" (Hales 2014, p. 63. My emphasis).

The tieredness of this model is plainly visible: the target belief is justified by basic beliefs which we find by applying a particular method. Since the Christian and the philosopher use different methods, they start from different basic beliefs (this is of course not necessary, it is just what happens in the case we are examining), which in turn, justify their opposing doxastic attitudes towards a target proposition.

Assuming that justification must be tiered generates two related problematic assumptions. First, that there are two realms which could be separated: in Hales's case, a method, and the beliefs generated by such method. As we saw before, when a belief generated by the method is central to its doctrine, the assumption of separatedness is hopeless. Secondly, the assumption that our disagreement is located in a fundamental difference: in Hales's account, it would be in our methods of acquiring basic beliefs. This assumption generates the misleading thought that if we only coincided on that particular point, then we would be on the same page. If the philosopher believed that the Bible is authoritative with respect to the existence of souls, then he would agree with his counterpart that humans have souls. However, for him to come to that one belief about the authority of religious texts, he would have to take on board a host of other beliefs.

These assumptions provide an illusory support for the kind of relativistic resolution strategy Hales defends; they make it look possible for disputants to recognise the relative truth of their counterpart's position. But, when the relativist attempts to prescribe the doxastic attitude the disputants must have in order to resolve their disagreement, she runs into problems.

\subsection{Some Disagreements Cannot Be Rationally Resolved}

A crucial difference between Hales's and Fogelin's theories concerns the resolution of disagreements. Hales argues that all disagreements are resolvable. In fact, his whole argumentation hinges on this, as he claims that relativism is the only resolution strategy available for certain kinds of disagreements. If the possibility of deep disagreements being beyond resolution were on the table for Hales, then that relativism is the only resolution strategy available for these disagreements would be a weaker motivation than he intends. Fogelin, however, does not assume, but in fact denies, that all disagreements are rationally resolvable.

Against Fogelin, the criticism might be made that if what we are after is a theory of disagreement resolution, the concession that some disagreements cannot be resolved, is throwing the towel and limiting the scope of one's own theory. I want to say two things about this.

Firstly, it is not clear that a theory of disagreements has to be a theory of disagreement resolution. The study of disagreements is valuable to epistemology because it offers opportunities to explore important questions of epistemic permissibility, rationality, justified beliefs, etc. It is disagreements whose resolution seem dim which bring these issues to the foreground in the clearest way. To assume that all disagreements can be rationally resolved is to skew the very same questions we aimed to answer.

Secondly, the fact that all resolution strategies surveyed by Hales (including relativism) fail to give an appropriate account of deep disagreement, warrants the consideration of their being incapable of rational resolution. Granted, we shouldn't go there unless our hand is forced, but that is exactly the situation we find ourselves in.

The possibility that deep disagreements remain unresolved prevents the problems I pointed out concerning Hales's theory: the impossible demand disappears because the hope of resolution disappears. In the framework of Fogelin's theory, disputants do not have to concede either that the truth-value of the proposition they disagree about is relative, 
or that the epistemic perspective of their adversary is prima facie tenable.

\subsection{Deep Disagreement as a Clash of Framework Propositions}

Fogelin says many things to characterise deep disagreements, which appear to pull in different directions. Some characterizations are compatible with Hales's theory; for example, the absence of "shared procedures for resolving disagreements" (Fogelin 1985/2005, p. 6). Among what is mutually acknowledged by the parties in a normal disagreement, are the ways to resolve it. Using Fogelin's own example, if you and I disagree about whether Rod Carew hit more triples than George Brett in 1984, we can settle the disagreement by consulting official record books that, while they can contain errors, are authoritative and have a "privileged status in discussions of past athletic achievements" ( p. 6). Consulting specialized literature constitutes an appropriate method to resolve the disagreement for both of us. In deep disagreements, in contrast, there is no mutually acknowledged way out of the dispute.

In Hales's case, agreement over meta-evidence (or second-order evidence) constitutes a procedure for resolving disagreements (as in the example of the disagreement over the age of the earth, 2014, p. 78-79). Hence, like Fogelin, Hales thinks irresolvability in disagreement is due to the absence of resolution procedures.

A different route to reconcile Fogelin's and Hales's positions is by using Fogelin's talk of deep disagreements being a "clash of framework propositions" (1985/2005, p. 8). According to Fogelin, when we assume the same framework propositions, we enter a normal disagreement. Thus, when our background commitments clash, the conditions for argumentation are not produced: "We get a deep disagreement when the argument is generated by a clash of framework propositions" (p. 8).

If we understand something like "the method of rational intuitions is the appropriate method to acquire beliefs about the existence of souls" as a framework proposition, then Hales's disagreement can also be considered a clash of framework propositions. We can even say that our allegiance to a set of framework propositions defines the doxastic method(s) we use. For example, the framework proposition "the Bible is authoritative over the question of the existence of the soul" partly constitutes a distinctively Christian methodology for acquiring beliefs.

Fogelin's talk of framework propositions can make for a tiered interpretation of deep disagreement: the proposition about which we disagree ("humans have souls") is the result of our holding different framework propositions, just as in Hales's account they are the result of different belief-acquiring methods. This account of deep disagreements is not only compatible with, but is quite close to, Hales's theory.

I believe that this reading of Fogelin's use of "framework propositions" is misguided, because Fogelin's talk of framework propositions is more nuanced than is visible here. For Fogelin, certain propositions delimitate "the framework or the structure within which reasons can be marshaled" (1985/2005, p. 5): "The arguments on each side are carried on within the framework of such commitments" (p. 11, my emphasis). I find this position a close rendering of Wittgenstein's On Certainty: "The system is not so much the point of departure, as the element in which arguments have their life" $(O C \S 105)$. Thus, the interpretation of framework propositions as the point of departure for arguments not only generates a tiered conception of deep disagreements (with its misleading assumptions), but doesn't seem a plausible interpretation of Fogelin's words.

Instead, I think it is better to connect his use of framework propositions with his appeal to "forms of life":

"when we inquire into the source of a deep disagreement, we do not simply find isolated propositions, but instead a whole system of mutually supporting propositions (and paradigms, models, styles of acting and thinking) that constitute, if I may use the phrase, $a$ form of life." (Fogelin 1985/2005: 9 my emphasis; this position is developed in Godden and Brenner 2010).

It is not, though, that participants of deep disagreements have different forms of life, and thus will never entertain normal disagreements. Rather, Fogelin talks of forms of life in the plural: "a person participates in a variety of forms of life that overlap and crisscross in a variety of ways. Some of these forms of life have little to do with others. This explains why we can enter into discussions and reasonable arguments over a wide range of subjects with a person who believes, as we think, things that are perfectly mad" (ibid.). ${ }^{11}$

Framework propositions are special only in that they encapsulate a key aspect of a form of life (like "humans have souls" does with the Christian form of life). Thus, the real reason behind the lack of a shared background in deep disagreement is disputants' belonging to different forms of

\footnotetext{
${ }^{11}$ We find practically the same point when Fogelin defends pluralistic contextualism: "I also think pluralistic contextualism is a more plausible view than holistic contextualism because pluralism squares with the undoubted fact that human beings can radically disagree with each other in certain areas, yet still understand and agree with each other over a very wide range of other topics. It is even possible for such mutual understanding to exist between people with fundamentally different worldviews. That my tax accountant subscribes to a religion that I find wholly irrational does not lead me to question his ability to prepare my tax return. Indeed, our disagreement on religion, though total, usually touches little else.” (Fogelin 1994, p. 209).
} 
life. What is, for me, so misleading about talk of framework propositions, is that it gives the impression that the disagreement is located in a belief (of the framework proposition). Alternatively, in Fogelin's (and, in some contexts, Wittgenstein's) sense, deep disagreements are distributed over different forms of acting (including thinking, judging, and believing) that constitute a form of life.

\subsection{Lateral Support in Lieu of Tiered Support}

If my interpretation of Fogelin's article is on the right track, the structure of deep disagreement it presents is significantly different from that presented by Hales. The belief of the disputants is not caused by anything more fundamental, because believing in e.g. the existence of souls, is not a consequence of having a certain form of life, it $i s$ part of a form of life. In this context, the three assumptions seen before, tieredness, separatedness, and locatedness, are nowhere to be found in this interpretation of Fogelin's view.

In the last part of this essay, I sketch the broad strokes of this alternative view.

Inspired by Fogelin's quoted passage, I am going to use the following notion of deep disagreements:

Deep disagreements: disagreements that, as they stand, cannot be argumentatively resolved ${ }^{12}$ because they are about propositions embedded in systems of mutually supporting propositions which are not (largely) shared by the disputants. $^{13}$

This characterization points to an aspect that will prove to be important: the idea that beliefs can gain support from other beliefs which are epistemically on a par, a kind of lateral support in lieu of tiered support.

When Jack disagree with Diane about the existence of souls, their disagreement is not located in this particular proposition (or in any step more basic), but rather it is distributed in a cluster of interrelated propositions. Because the attitude disputants have towards the target proposition (belief or disbelief) is rooted in the support further beliefs give it, distinction between target belief and its system is unattainable. This explains why participants in deep disagreements

\footnotetext{
12 I changed Fogelin's denial of rational resolution for argumentative resolution following Turner and Wright's (2005) cue that we separate Fogelin's "modest claim" that deep disagreements are not resolvable with arguments, from his "radical claim" that they cannot be rationally resolved (p. 26). We could therefore find non-argumentative rational resolution methods for deep disagreements.

13 Notably, "paradigms, models, styles of acting and thinking" are lacking from my characterization. This is not because I think these are not to be found in deep disagreements. But, rather, because I want to show that even when we only consider beliefs, deep disagreements can arise.
}

won't conceive of the other party's position as relatively true, but rather as profoundly mistaken.

This interpretation does not run into the problems raised by Hales's view, because disputants do not have to comply with condition (d): that each disputant must separate the proposition believed by her adversary from the epistemic perspective motivating and justifying it - taking the proposition to be false, while taking the perspective to be tenable. On my view, there are no perspectives we need to judge, just interrelated beliefs. In this outlook, the target belief cannot be considered in isolation to the other propositions it is connected to; one has to take into account the form a life in which such proposition is embedded in, if one wants to understand what is being believed. Fogelin illustrates this point in his discussion of abortion as a deep disagreement: "someone will hold that at conception, or to be delicate, very shortly after conception, an immortal soul enters into the fertilized egg, and with this, personhood is attained. Why should one believe anything like this? Well, this is part of a wider tradition..." (1985/2005, p. 8).

If we only have beliefs that are interrelated, then separation between target belief and the system it is embedded into seems hopeless, and the disagreement is better described as distributed over a cluster of interrelated beliefs, rather than located in a fundamental epistemic resource. Finally, if all we have are interconnected beliefs, the only kind of support a proposition can gain is lateral, that is, from other beliefs that are epistemically on a par, rather than tiered because there is no proposition with an especial epistemic pedigree. Which brings me to another aspect I find misleading of talk of framework propositions; it suggests the idea that the special role framework propositions play in the form of life they are embedded in, is due to their being better grounded. What my reasoning so far suggests, on the other hand, is that their support does not come from their being more fundamental, but from being interrelated to other beliefs (and models, values, paradigms, and styles of acting and thinking). There is nothing special about framework propositions other than the role they play in our forms of life.

\subsection{The Soul Disagreement as Deep Disagreement}

My rendering of deep disagreement says that they that they are irresolvable because the target belief is embedded into a system of mutually supporting propositions which is not shared by the disputants. Why is the irresolvability 
connected to the lack of shared beliefs? The answer was already hinted at in my initial exposition of Fogelin's position. The "language of argument", Fogelin tells us, "has its primary application in the context of a normal or near normal argumentative exchanges" $(1985 / 2005$, p. 6). When the relevant beliefs the disputants have on a certain topic are radically different, "conditions for argument do not exist. The language of argument may persist, but it becomes pointless since it makes an appeal to something that does not exist: a shared background of beliefs and preferences" (p. 7). Disputants use bits of language in ways that imitate their use in a language of arguments and arguing, but it cannot be properly said that they are giving "reasons", since what reasons are is a function of the shared background beliefs.

When the Christian of our example cites passages from the Bible, quotes from reputable theologians, or appeals to mystic intuition as reasons for her belief that humans have souls, the atheist will not register those as reasons (or as evidence), since the background beliefs which permit that they are considered reasons is lacking. This explains why both sides of the dispute are essentially untouched by it, nothing said from the other side was even remotely compelling. ${ }^{14}$ In a way, this is not really a case of an actual argumentative exchange, but rather a simulacrum of an argument.

\section{Conclusion}

There are two distinct parts of this paper. In the first, my aim was to closely examine and scrutinise Hales's argument for the plausibility of the relativistic resolution strategy in cases of epistemically intractable disagreements. My verdict was negative; the strategy needs some preconditions to work, which disputants are not able to meet.

My aim in this project, however, was not entirely negative. I tried to provide a hypothesis of why the strategy failed, and why it seemed possible to begin with: By conceptualizing our doxastic activity as a tiered affair, it gives the impression that belief and perspective can be separated, and that the disagreement is located in the latter.

I presented a (very rough) characterization of what an alternative model would be like inspired by Fogelin's remarks on deep disagreements. Our beliefs are interconnected in a way that they gain support from each other. Thus, the belief we disagree about is not rooted in a more fundamental resource, but rather it gains a kind of lateral support from the system i.e. form of life it belongs to. Since the

\footnotetext{
14 I don't mean to imply that all argumentative exchanges between theists and atheists are deep. There are less radical positions which could allow for an important set of the disputants' relevant beliefs to be shared, which would result in different ways for the disagreement to be resolved (capitulation or compromise as the most likely). However, this would obviously not constitute a deep disagreement.
}

system is the element "in which arguments have their life" (Wittgenstein 1969, § 105), participation in different forms of life undercut the very conditions for argumentation; viz., a shared background of beliefs and preferences. In this scenario, the arguments on each side do not affect the other, and the disagreement remains unresolved.

Acknowledgements Open access funding provided by University of Vienna. I would like to thank Katharina Bernhard, Ignacio Cervieri, Matías Gariazzo, Victoria Vázquez, Ignacio Vilaró, and specially Martin Kusch for their comments on previous versions of this paper.

Open Access This article is distributed under the terms of the Creative Commons Attribution 4.0 International License (http://creativeco mmons.org/licenses/by/4.0/), which permits unrestricted use, distribution, and reproduction in any medium, provided you give appropriate credit to the original author(s) and the source, provide a link to the Creative Commons license, and indicate if changes were made.

\section{References}

Baghramian M, Carter JA (2017) Relativism. The Stanford encyclopedia of philosophy. Retrieved 2 Aug 2017 from https://plato.stanf ord.edu/archives/sum2017/entries/relativism/

Boghossian P (2006) Fear of knowledge. Clarendon Press, Oxford

Boghossian P (2011) Three kinds of relativism. In: Hales S (ed) A companion to relativism. Blackwell, Oxford

Finocchiaro M (2013) Meta-argumentation: an approach to logic and argumentation theory. College Publications, London

Fogelin R (1985) The logic of deep disagreements. Informal Log 7(1):1-8 [Reprinted in (2005) Informal Log 25:3-11 the page references are to the 2005 edition]

Fogelin R (1994) Pyrrhonian reflections on knowledge and justification. Oxford University Press, Oxford

Godden D, Brenner W (2010) Wittgenstein and the logic of deep disagreement. Cogency 2:41-80

Hales SD (2004) Intuition, revelation, and relativism. Int J Philos Stud 12(3):271-295

Hales SD (2006) Relativism and the foundations of philosophy. MIT Press, Cambridge

Hales SD (2014) Motivations for relativism as a solution to disagreements. Philosophy 89(1):63-82

Hazlett A (2013) Entitlement and mutually recognized reasonable disagreement. Episteme 11(1):1-25

Kinzel K, Kusch M (2018) De-idealizing disagreement, rethinking relativism. Int J Philos Stud. https://doi.org/10.1080/09672 559.2017.1411011

Lynch MP (2010) Epistemic circularity and epistemic incommensurability. In: Haddock A, Millar A, Pritchard D (eds) Social epistemology. Oxford University Press, Oxford

Lynch MP (2012) In praise of reason. MIT Press, Cambridge

Pritchard D (2011) Epistemic relativism and wittgensteinian epistemology. In: Hales SD (ed) A companion to relativism. Wiley, New York

Rovane C (2011) Relativism requires alternatives, not disagreement or relative truth. In: Hales SD (ed) A companion to relativism. Wiley, New York

Turner D, Wright L (2005) Revisiting deep disagreement. Informal $\log 25(1): 25-35$

Wittgenstein L (1969) On certainty. Harper and Row, New York 